\title{
Investigation into Mechanism of Floor Dynamic Rupture by Evolution Characteristics of Stress and Mine Tremors: A Case Study in Guojiahe Coal Mine, China
}

\author{
Guangjian Liu $(\mathbb{D}$, Zonglong Mu $(\mathbb{D}$, Atif Javed, Shaokun Gong, Jing Yang, and Jinglong Cao \\ State Key Laboratory of Coal Resources and Safe Mining, School of Mines, China University of Mining and Technology, Xuzhou, \\ Jiangsu 221116, China \\ Correspondence should be addressed to Zonglong Mu; muzonglong@163.com
}

Received 19 November 2017; Revised 23 February 2018; Accepted 25 March 2018; Published 30 April 2018

Academic Editor: Longjun Dong

Copyright (C) 2018 Guangjian Liu et al. This is an open access article distributed under the Creative Commons Attribution License, which permits unrestricted use, distribution, and reproduction in any medium, provided the original work is properly cited.

\begin{abstract}
In order to explore the mechanism of floor dynamic rupture, the current study adopts a thin plate model to further investigate the condition of floor failure. One of the possible explanations could be floor buckling due to high horizontal stress and dynamic disturbance ultimately leading to rapid and massive release of elastic energy thus inducing dynamic rupture. Seismic computed tomography and 3D location were employed to explore the evolution characteristics of floor stress distribution and positions of mine tremors. In the regions of floor dynamic rupture, higher P-wave velocity was recorded prior to the dynamic rupture. On the contrary, relatively lower reading was observed after the dynamic rupture thus depicting a high stress concentration condition. Meanwhile, evolution of mine tremors revealed the accumulation and subsequent release of energy during the dynamic rupture process. It was further revealed that dynamic rupture was induced due to the superposition of static and dynamic stresses: (i) the high static stress concentration due to frontal and lateral abutment stress from coal pillar and (ii) dynamic stress from the fracture and caving of coal pillar, hard roof, and key stratum. In the later part of this study, the floor dynamic rupture occurrence process would be reproduced through numerical simulations within a $0.6 \mathrm{sec}$ time frame. The above-mentioned findings would be used to propose a feasible mechanism for prewarning and prevention of floor dynamic rupture using seismic computed tomography and mine tremors 3D location.
\end{abstract}

\section{Introduction}

Recently, demand for fossil fuel, especially coal, has been increasing rapidly in China and worldwide. Presently, underground mining operations have been increasing their operational depth at an annual rate of $10-20 \mathrm{~m}$ [1]. In deep mining, floor heave is the principal part of roadway deformation failure [2]. In recent years, several scholars have adopted various methods to study floor failure, for example, numerical simulation (UDEC), laboratory experiments, and in situ tests. For example, Jiang et al. [3] explored the floor rupture mechanism using theoretical analysis as well as a similarity simulation test. Since 2001, more and more researchers have adopted many numerical simulations to research floor rupture mechanism and its control indices and method [48]. Jeon et al. [9] studied excavation-related problems with application of small model testing. Lee and Schubert [10] investigated the roadway faces failure mechanism by conducting small scale model tests. S. B. Tang and C. A. Tang [11] adopted numerical simulations to study the impact of humid conditions on the floor rupture of roadway in the swelling ground. Zhong et al. [12] conducted various field investigations and geological surveys to analyze the floor rupture occurrence mechanism for soft-rock roadways. Evidently, the floor process mentioned in the above literatures is timeaffected, completion of which usually involves considerable time period ranging from hours to days and even months. However, its instant occurrence and resulting energy release could induce dynamic rupture.

High pressure levels trigger violent rock failure which could also be associated with strong seismic activity. In other words, a dynamic rupture might occur upon total stress attainment of a certain critical stress value (due to the static stress of roadway combined with the tremors induced 


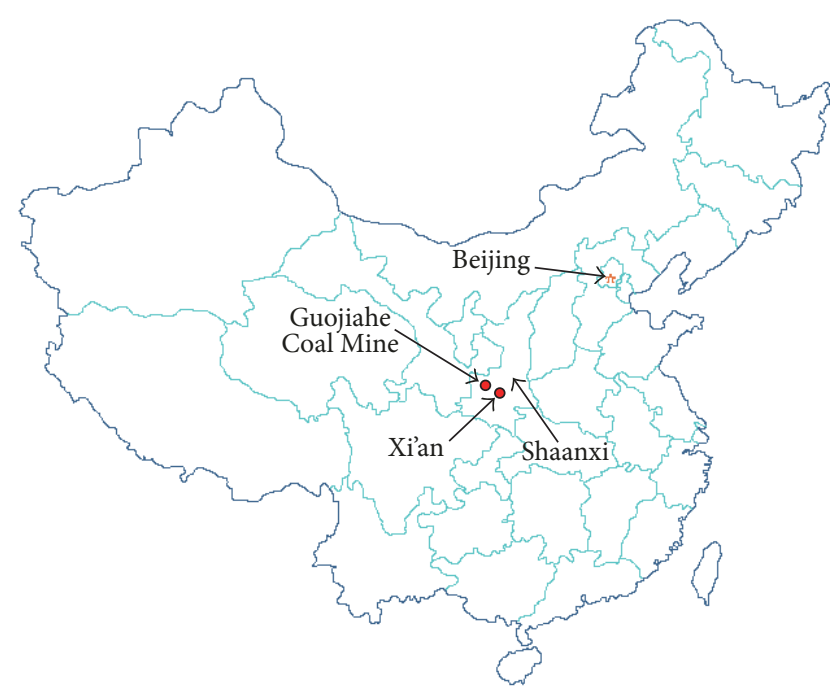

Figure 1: The geographical location of Guojiahe Coal Mine. It is located in Baoji, Shaanxi, China.

dynamic stress) [13]. Unfortunately, dynamic rupture events in recent past had posed severe threats to mine workers thus adversely affecting continuous production in coal mines [1]. In recent years, many scholars have studied dynamic rupture induced by hard rock [14], coal pillar $[15,16]$, fault $[17,18]$ and tectonic stress $[19,20]$, employing stress, strain and energy, and so forth as frequently used parameters but very few literatures had focused on floor dynamic rupture. This paper investigates mechanical mechanism of floor dynamic rupture by adopting an elastic thin plate theory. The seismic computed tomography methods and 3D location of mine tremors were used in the case study in Guojiahe Coal Mine. Numerical simulation was adopted to reproduce the floor dynamic rupture process owing to its geological setting.

\section{A Case of Floor Dynamic Rupture}

2.1. General Situation of the 1307 LCF. The 1307 LCF is located in the first panel of the Guojiahe Coal Mine, situated in Shaanxi, Baoji, China (Figure 1). Its west is 1301 LCF (mined), north is 1303 and 1305 LCFs (mined), and the south is 1309 LCF (unmined). With the lengths of $1387 \mathrm{~m}$ and $235 \mathrm{~m}$ in strike and sloping, the maximum mining of the coal face has depth of $586 \mathrm{~m}$. The mining seam is $3 \#$ coal with thickness of $7-17.7 \mathrm{~m}$ (average is $14.3 \mathrm{~m}$ ) and average dip angle of $10^{\circ}$. According to geological survey, in the 1307 LCF, the immediate roof is fine sandstone $(6.12 \mathrm{~m})$, main roof is siltstone $(6.28 \mathrm{~m})$, the key stratum is medium sandstone $(27.72 \mathrm{~m})$, and immediate floor $(12.5 \mathrm{~m})$ and the main floor $(12.5 \mathrm{~m})$ are siltstone. The spacing between $3 \#$ coal seam and upward key stratum is $37.79 \mathrm{~m}$. The mining period was from July 10, 2016, till April 4, 2017, with total advancing distance of $1053 \mathrm{~m}$. A $30 \mathrm{~m}$ wide coal pillar was left out between the 1305 and 1307 LCFs. Figure 2 shows the plane sketch of the 1307 LCF whereas Figure 3 depicts the illustration of coal and rock layers. Using the laboratory burst proneness identification method, the main roof; floor; and 3\# coal seam were classified as prone to weak burst.

2.2. MS Monitoring System. The sources of in situ data were utilized to obtain the details of dynamic disturbance. The sources were monitored by Seismological Observation System (SOS). It was developed by Poland Central Mining Institute and was installed at Guojiahe Coal Mine on October 1, 2016, which mainly consists of the real-time monitoring recorder, analyzer, sensors, the digital transmission system, and so forth [21]. The frequency range of single verticalcomponent sensor is $1-600 \mathrm{~Hz}$, horizontal location error is less than $20 \mathrm{~m}$, vertical positioning error is less than $30 \mathrm{~m}$, the sampling rate is $500 \mathrm{~Hz}, \mathrm{~A} / \mathrm{D}$ converter is 16 bits, the maximum data transmission rate is $1 \mathrm{MB} / \mathrm{s}$, and the maximum data transmission distance is $10 \mathrm{~km}$. In addition, the system uses the triggering mode for recording event. Only when more than four sensors simultaneously receive a clear waveform, the MS event can be recorded and accurately located. The following study is based on Microseismic (MS) signals monitored by SOS system mentioned above.

2.3. Process and Description of the Dynamic Rupture. At $19: 24: 14$ on April 4, 2017, a mine tremor of magnitude 1.9 occurred in the $1307 \mathrm{LCF}$, and the estimated energy release was $2.55 \times 10^{5} \mathrm{~J}$. The coordinates in $x, y$, and $z$ directions were $7914.18 \mathrm{~m}, 2137.98 \mathrm{~m}$, and $798.71 \mathrm{~m}$, respectively. According to the source's horizontal coordinates, mine tremor was verified to be in area A (see Figure 2), influenced by three factors of coal pillar, synclinal axial part, and the square (the 1303, 1305, and 1307 LCFs), respectively. Based on the source's vertical level, it was verified that the mine tremor was directly induced by fracturing in key stratum (area A) overlying 3\# coal seam. Approximately less than 1 second later, a floor dynamic rupture of magnitude 1.76 was observed in the tailentry and local $1307 \mathrm{LCF}$, and the estimated energy was $2.55 \times 10^{5} \mathrm{~J}$, as shown in Figure 2. Prior to the dynamic rupture, several mine tremors occurred with the calculated energy more than $1.0 \times 10^{5} \mathrm{~J}$ also located in the coal pillar thus indicating association of dynamic rupture with fracturing of key stratum and coal pillar. After dynamic rupture occurrence, a scraper conveyor was jacked in the tailentry up to $400 \mathrm{~mm}$ in the 1307 LCF, and a hydraulic prop was inserted into the bottom and top coal with dynamic rupture value up to $600 \mathrm{~mm}$. The shock wave also caused some machines to shut down. The three-dimensional coordinates of the sensors were shown in Table 1.

\section{Mechanism of Floor Dynamic Rupture}

In a coal mine, presence of soft rock, coal seam, or weak interlayer leads to formation of a composite floor. Due to accumulation of elastic energy, the high horizontal stress would cause the floor to buckle thus inducing floor heave [22]. Additionally release of massive elastic energy would lead to occurrence of dynamic rupture. This study establishes a mechanical model of composite floor to study the buckling criterion. Hence, dynamic rupture mechanical mechanism was investigated based on elastic thin plate model. 


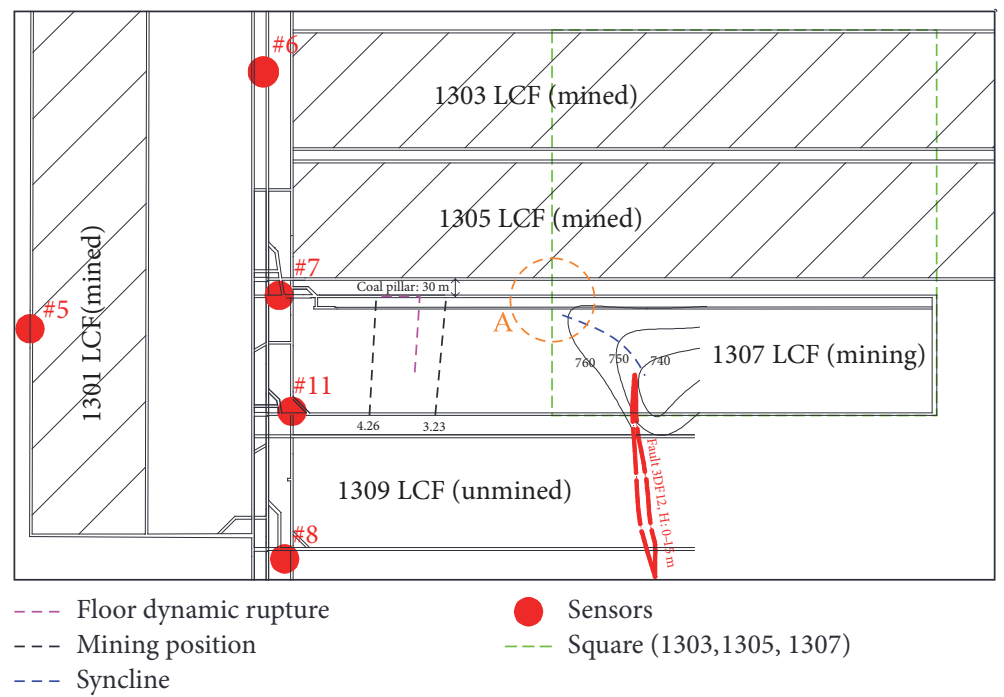

FIGURE 2: The plane sketch of coal burst in the 1307 LCF. It contains five LCFs and five sensors and mining geological conditions.

TABLE 1: Relative coordinates of sensors.

\begin{tabular}{lccc}
\hline Sensor number & $x$-coordinate $(\mathrm{m})$ & $y$-coordinate $(\mathrm{m})$ & $z$-coordinate $(\mathrm{m})$ \\
\hline 5 & 6862.16 & 2060.89 & 730.1 \\
6 & 7409.71 & 2589.06 & 767.8 \\
7 & 7441.5 & 2131.7 & 767.8 \\
8 & 7465.66 & 1567.24 & 643.3 \\
11 & 7447.68 & 1894.06 & 724.45 \\
\hline
\end{tabular}

\begin{tabular}{|c|c|c|c|c|}
\hline Lithology name & $\begin{array}{c}\text { Geological } \\
\text { Formations }\end{array}$ & $\begin{array}{c}\text { Level } \\
(\mathrm{m})\end{array}$ & $\begin{array}{l}\text { Thickness } \\
(\mathrm{m})\end{array}$ & Notes \\
\hline Fine sandstone & & 830.41 & 11.63 & \\
\hline $\begin{array}{l}\text { Medium } \\
\text { sandstone }\end{array}$ & & 802.69 & 27.72 & Key stratum \\
\hline Fine siltstone & & 796.87 & 5.82 & \\
\hline Siltstone & & 790.04 & 6.83 & \\
\hline Mudstone & & 782.6 & 7.44 & \\
\hline 2\# coal & & 781.05 & 1.55 & \\
\hline Fine sandstone & & 774.77 & 6.28 & Main roof \\
\hline Siltstone & & 768.65 & 6.12 & $\begin{array}{c}\text { Immediate } \\
\text { roof }\end{array}$ \\
\hline Mudstone & & 764.9 & 3.75 & \\
\hline 3\# coal & & 750.6 & 14.3 & Mining \\
\hline Siltstone & - & 738.1 & 12.5 & \\
\hline Fine sandstone & & 730.52 & 7.58 & \\
\hline
\end{tabular}

Figure 3: Geological formations in the 1307 LCF. The mining coal seam is $3 \#$ coal.

3.1. Elastic Thin Plate Model. Figure 4 depicts sketch prior to and after dynamic rupture. From Figure 4, assuming that the first layer $\left(h_{1}\right)$ had been fractured completely, the composite floor is a simply supported plate, with the thickness of $h_{1}, h_{2}, \ldots, h_{n}$. Figure 5 is sketch map of elastic thin plate theory with simply supported plate [23]. The thickness is $h$; the length along the cross section of roadway is $a$ with force of $P_{x}$; the length along the axial of roadway is $b$ with force of $\alpha P_{x} ; \alpha$ is lateral pressure coefficient; and bending rigidity is $D$.

3.2. Mechanical Mechanism. According to elasticity, if buckling damages the thin plate, the stress differential equation could be written as follows [24]:

$$
D \nabla^{4} \omega-\left(N_{x} \frac{\partial^{2} \omega}{\partial x^{2}}+2 N_{x y} \frac{\partial^{2} \omega}{\partial x y}+N_{y} \frac{\partial^{2} \omega}{\partial y^{2}}\right)=0
$$

where $N_{x}$ is the force in $x$-direction; $N_{y}$ is the force in $y$ direction; $N_{x y}$ is the sheer force; $\omega$ is deflection.

The force in the thin plate could be obtained as

$$
\begin{aligned}
N_{x} & =-P_{x}, \\
N_{y} & =-\alpha P_{x}, \\
N_{x y} & =0 .
\end{aligned}
$$

For the sake of simplicity, assume $b=1$ and the deflection of thin plate as follows [24]:

$$
\omega=\sum_{m=1}^{\infty} A_{m} \sin \frac{m \pi x}{a}
$$




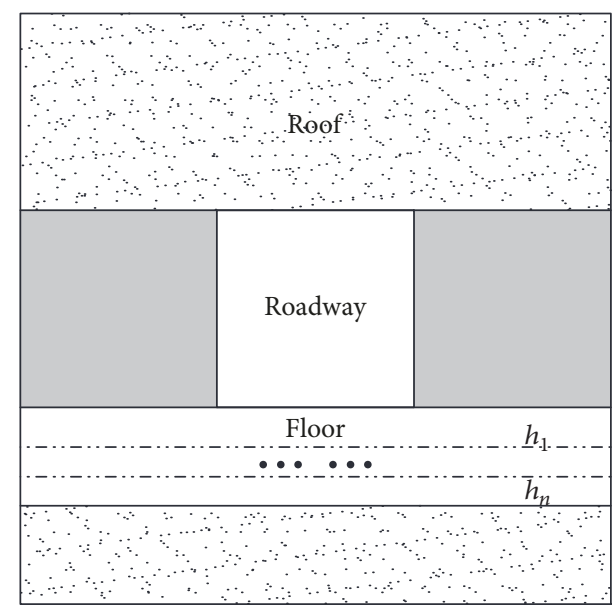

(a)

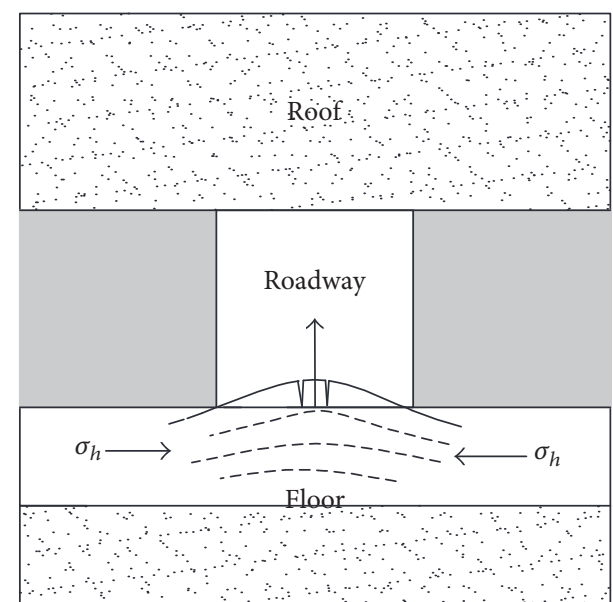

(b)

FIGURE 4: The sketch before and after floor dynamic rupture. Note: (a) before and (a) after.

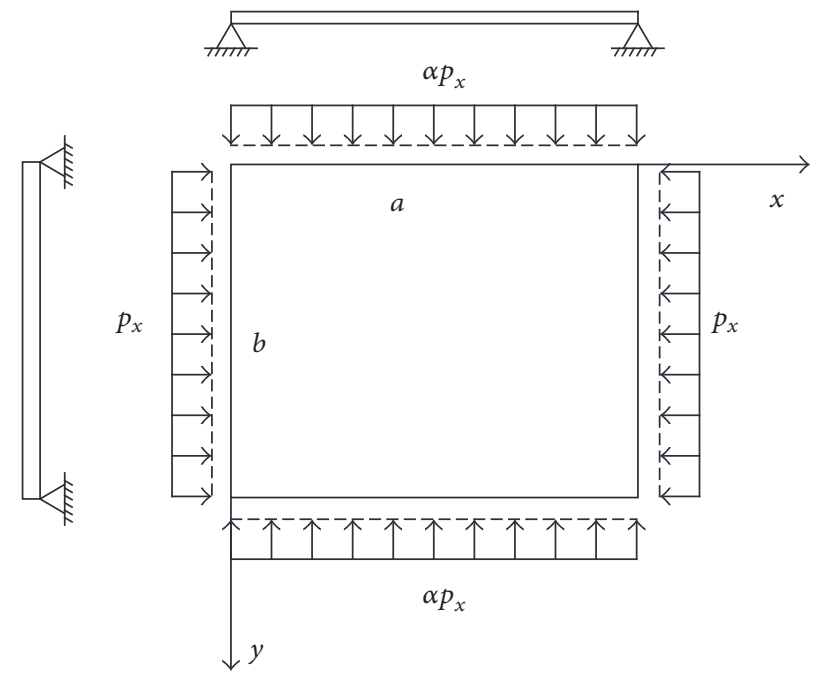

FIGURE 5: The sketch map of elastic thin plate theory. Note: $a$ is the width of roadway; $b$ is the length and set as 1 .

where $A_{m}$ is the maximum deformation; $m$ is the characteristic value; $x$ is the horizontal coordinate.

Combining (1), (2), and (3),

$$
\sum_{m=1}^{\infty} A_{m}\left(\frac{D m^{4} \pi^{4}}{a^{4}}-p_{x} \frac{m^{2} \pi^{2}}{a^{2}}\right) \sin \frac{m \pi x}{a}=0 .
$$

Solving (4),

$$
p_{x}=\frac{m^{2} \pi^{2}}{a^{2}} D .
$$

According to (5), as $m$ increases, $P_{x}$ would also increase. Assuming $m=1$, critical stress is obtained as follows:

$$
p_{\mathrm{cr}}=\frac{\pi^{2}}{a^{2}} D
$$

where $p_{\text {cr }}$ is the critical stress; $D$ is the bending stiffness of floor, $D=E h^{3} / 12\left(1-\mu^{2}\right)$; $E$ is the elasticity modulus; $\mu$ is Poisson's ratio; $h$ is the thickness.

Based on rock stress calculation method, the horizontal stress could be expressed as

$$
p_{h}=\sigma_{h} h
$$

where $p_{h}$ is the horizontal force; $\sigma_{h}$ is the horizontal stress.

Based on (6) and (7), the mechanical mechanism of heaving floor is as follows:

$$
\frac{p_{h}}{p_{\mathrm{cr}}}=\frac{12 \sigma_{h} a^{2}\left(1-\mu^{2}\right)}{E \pi^{2} h^{2}} \geq 1
$$

From (8), the factors of floor dynamic rupture are roadway width, floor thickness, modulus of elasticity, Poisson ratio, and horizontal stress. In Guojiahe Coal Mine, keeping the modulus of elasticity and Poisson ratio as constant, the risk of floor dynamic rupture is positively related to roadway width and horizontal stress, while being negatively related to the thickness. Therefore, the horizontal stress is the key factor to floor dynamic rupture.

3.3. Dynamic Rupture Induced by the Static Stress Combined with the Dynamic Stress. According to Li et al. [13], when total stress attains a certain critical stress level, it leads to occurrence of floor dynamic rupture:

$$
\sigma_{s}+\sigma_{d} \geq \sigma_{r}
$$

where $\sigma_{s}$ is the static stress in the floor which is due to high horizontal stress; $\sigma_{d}$ is the dynamic stress induced by occurrence of tremors due to hard roof, coal pillar and fault slip, and so forth; and $\sigma_{r}$ is the critical stress required for dynamic rupture. Hence, in the event of existence of mine tremors containing large energy, high horizontal stress could induce floor dynamic rupture. 


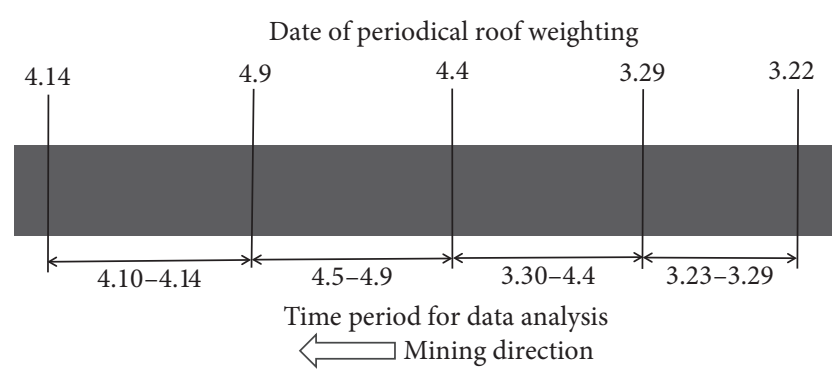

Figure 6: The time period for data analysis. The research time is from March 22 to April 14. On April 4, the floor dynamic rupture occurred.

\section{Evolution Characteristics of Mine Tremors Position and Stress Distribution}

As per monitoring stress in the $1307 \mathrm{LCF}$, the date of weighing of periodical roof is shown in Figure 6. The time periods for data analysis (3D location of mine tremors and seismic computed tomography) are also shown in Figure 6.

4.1. Mine Tremors Position: A 3D Location Approach. Parsons [25] reported a similar structural evolution of the systems which cause earthquakes. According to some scholars [2628], the position of Acoustic Emission (AE) events can be calculated using the following formulas:

$$
\begin{aligned}
\sqrt{\left(x_{i}-x\right)^{2}+\left(y_{i}-y\right)^{2}+\left(z_{i}-z\right)} & =S, \\
V & =\frac{S(1-\varepsilon)}{T_{2}-T_{1}},
\end{aligned}
$$

where $V$ is AE signal velocity $(\mathrm{m} / \mathrm{s}), T_{1}$ is the initial propagation time of AE signal (s), $T_{2}$ is the first-arrival time of $\mathrm{AE}$ signal at $\mathrm{AE}$ sensor (s), $S$ is the distance from $\mathrm{AE}$ source to sensor $(\mathrm{m}), \varepsilon$ is the strain of coal sample, $\left(x_{0}, y_{0}, z_{0}\right)$ are the three-dimensional coordinates of source, and $\left(x_{1}, y_{1}, z_{1}\right)$ are the three-dimensional coordinates of the $\# i$ sensor. Commonly, $i$ is numbered sequentially from 1 to $n$, and $n$ should be larger than 4 for positioning. The larger the number $n$ is, the more accurate the position is.

In order to reveal the location evolution of mine tremors prior to and after floor dynamic rupture in the 1307 LCF, the evolution of mine tremors distribution from March 23 to April 14 is illustrated (Figure 7). From Figure 7 it could be seen that majority of mine tremors were in regions of the coal pillar and roof, which initially indicated that the dynamic rupture might have been induced by the fracturing of coal pillar and periodical roof weighting.

As shown in Figure 7, from March 23 to March 29, majority of mine tremors were scattered in regions $\mathrm{B}$ and $\mathrm{C}$, which indicated that many fractures were induced by the frontal abutment stress and mining. Interestingly, region $\mathrm{B}$ had more mine tremors than region $\mathrm{C}$, which indicated that the mined out LCF possessed the ability to induce more severe fractures. A large number of mine tremors in region A indicated that mining influence renders the multiroadway cross area unstable. Additionally, several fractures were found out in floor, coal seam, and roof, but they were very few in the key stratum. Besides, several mine tremors, induced by syncline activities; coal pillar; and the first square (1303, 1305 , and $1307 \mathrm{LCFs}$ ), were discovered in region $\mathrm{D}$. The mine tremors (red) indicated fracturing and caving of key stratum [29-33].

From March 30 to April 4, more mine tremors were discovered in region A, indicating increase in fractures activity in the multiroadway cross area along with the advancement of mining face. Contrarily, the mine tremors (red) were reduced in regions $B$ and $C$, which indicated accumulation of energy in coal and rock mass for the dynamic rupture, while the increase (blue and yellow) was induced by the dynamic rupture in region B [29-31]. On April 4, the weighing of periodical roof took place. Hence, dynamic loading resulting from fracturing and caving of coal pillar and roof induced dynamic rupture. The mine tremors in region $\mathrm{D}$ remained unchanged.

From April 5 to April 9 (after dynamic rupture occurrence), steady distribution of mine tremors was observed in region of $\mathrm{A}, \mathrm{B}, \mathrm{C}$, and $\mathrm{D}$, with nonoccurrence of large energy mine tremors thus indicating significant energy release due to dynamic rupture. The mine tremors and the aftershocks (blue and yellow) were induced by roof instability and coal mining [32].

From April 10 to April 14, amplified mine tremor activity was recorded which indicated increasing fracture activity in regions $\mathrm{A}, \mathrm{B}, \mathrm{C}$, and D. Compared to preceding three periods, the larger mine tremors (yellow and red) indicated increased fractures occurrence in regions $\mathrm{A}, \mathrm{B}$, and $\mathrm{C}$ due to being a coal pillar [31-33].

4.2. Stress Distribution: A Seismic Computed Tomography Approach. The stress field in coal and rock mass in coal mines could be easily obtained by using theoretical calculation and numerical simulation. However, complex geological setting and mining activities make it extremely difficult to obtain the in situ stress field in time and space. To eradicate this problem, many researchers have studied the P-wave tomography for evaluating the high stress in coal mines [34-36].

Tomography requires dividing the body into grid cells called pixels in two-dimensional situation, or cubes called voxels in three-dimensional situation to estimate the body characteristics in all pixels or voxels. Velocity tomography depends on the relation that the wave velocity along a seismic ray is the ray path distance divided by the time to travel between the seismic source and sensor. Suppose the ray path of the $i$ th seismic wave is $L_{i}$ and the travel time is $T_{i}$; thus, the time is the integral of the inverse velocity (or slowness), multiplied by the distance traveled from the source to the sensor [37]:

$$
\begin{aligned}
V T & =L, \\
T_{i} & =\int_{L_{i}} \frac{d L}{V(x, y, z)}=\int_{L_{i}} S(x, y, z) d L, \\
T_{i} & =\sum_{j=1}^{m} d_{i j} S_{j} \quad(i=1, \ldots, n),
\end{aligned}
$$



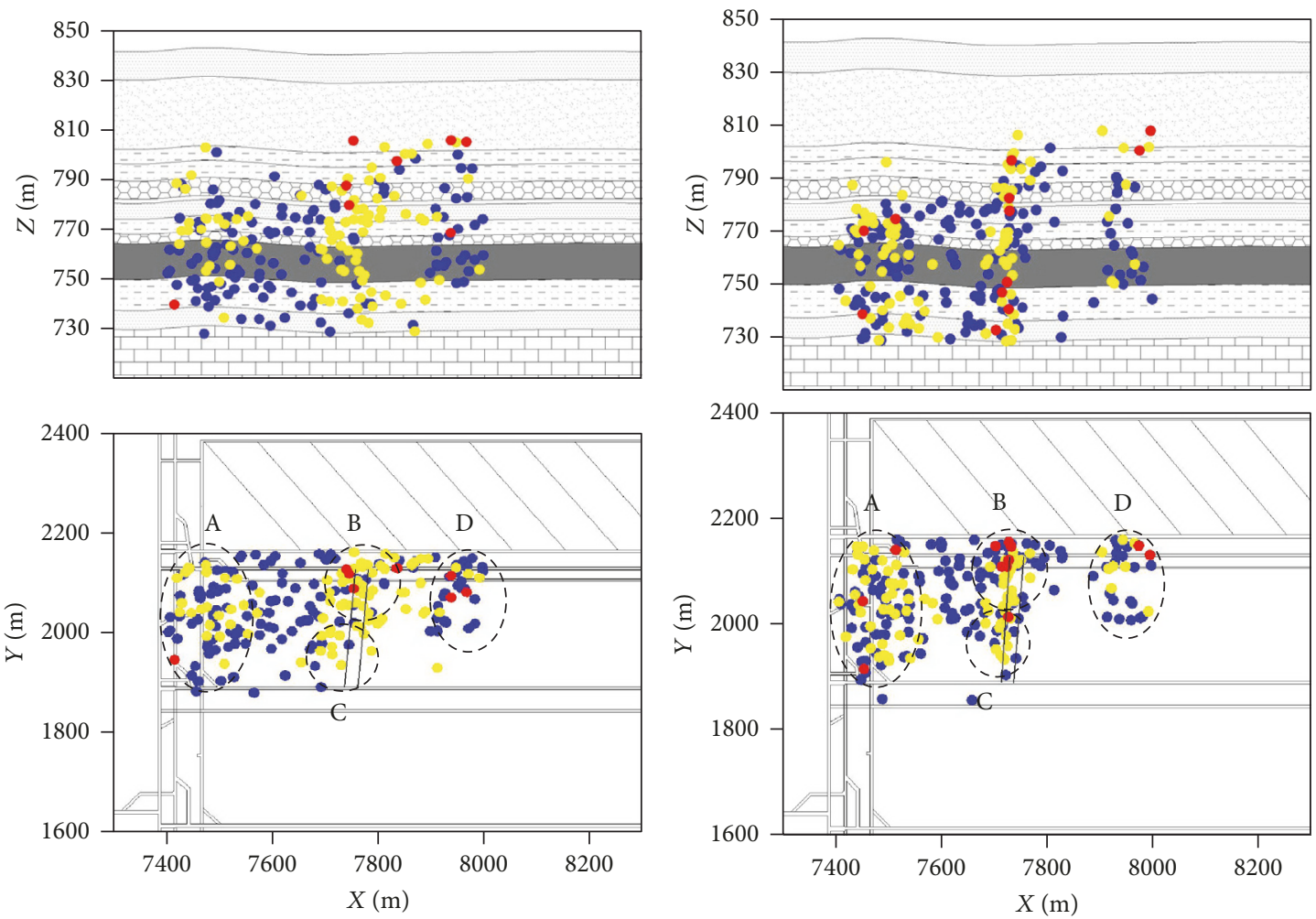

March 23-March 29

March 30-April 4
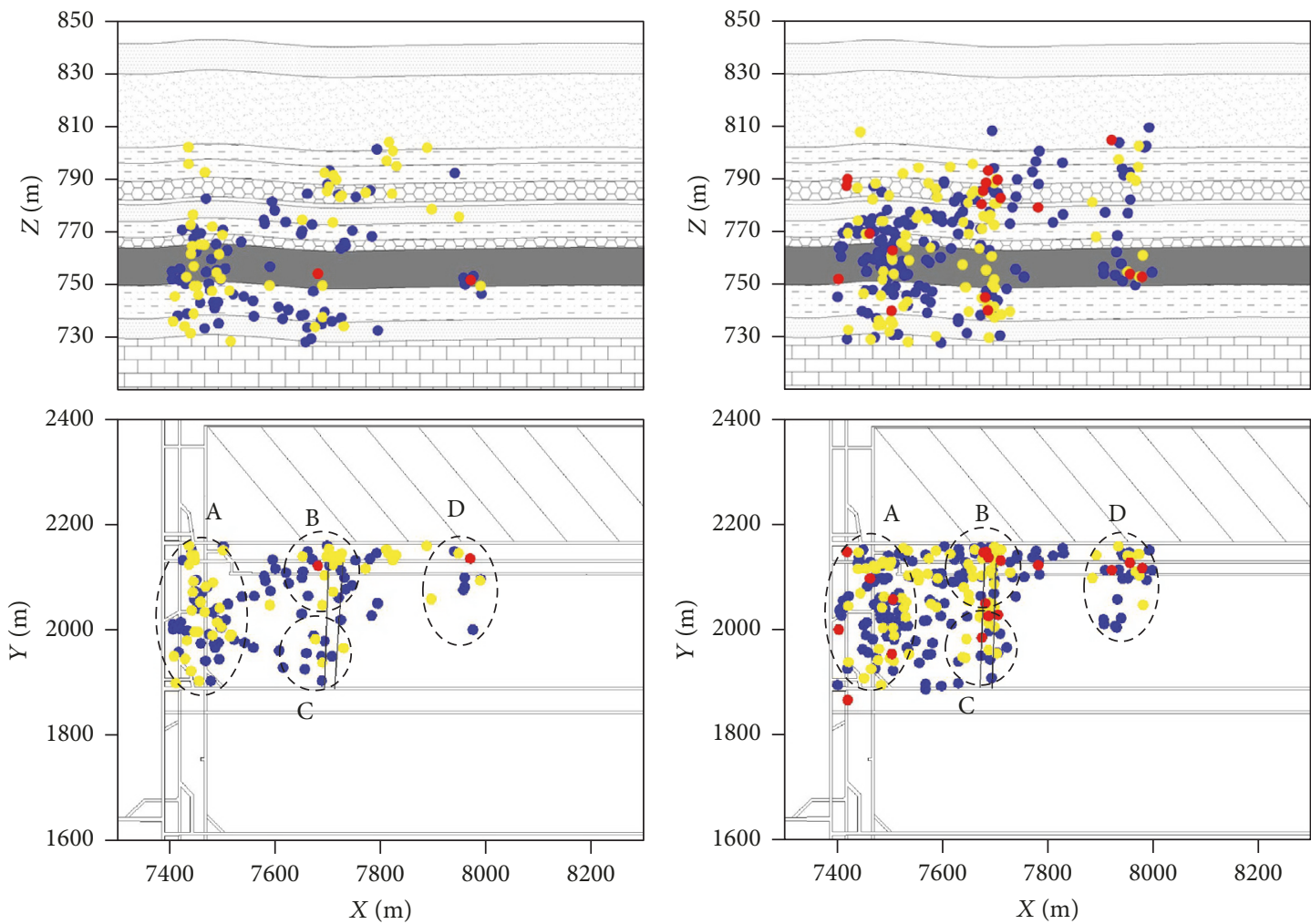

April 5-April 9

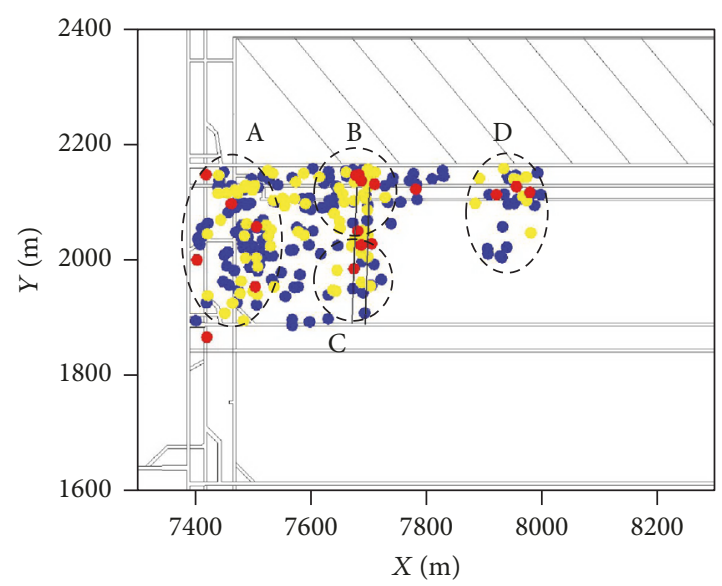

April 10-April 14

Figure 7: Location evolution of mine tremors with different energy ranges. Notes: blue: $0-10^{4} \mathrm{~J}$; yellow: $10^{4}-10^{5} \mathrm{~J}$; red: $>10^{5} \mathrm{~J}$. The floor dynamic rupture occurred in region $\mathrm{B}$. 


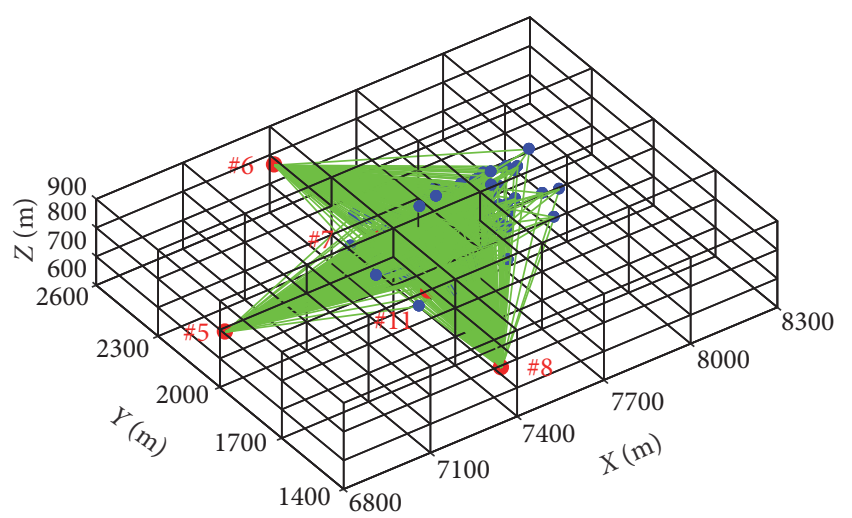

- Mine tremor

Raypath

- Sensor

FIgure 8: The tomographic modeling. The total mine tremors were 1519.

where $V(x, y, z)$ is the velocity $(\mathrm{m} / \mathrm{s}), L_{i}$ is the ray path of the $i$ th seismic wave (m), $T_{i}$ is the travel time (s), $S(x, y, z)$ is the slowness $(\mathrm{s} / \mathrm{m}), d_{i j}$ is the distance of the $i$ th ray in the $j$ th voxel, $n$ is the total number of rays, $m$ is the number of voxels.

Generally, seismic event location and subsequent ray path are calculated using an initial velocity model. However, the velocity, distance, and time in an individual voxel are not known. Thus, arranging the slowness, distance, and time for each voxel into matrices, the velocity can be determined in matrix form as [37]

$$
\mathrm{T}=\mathrm{DP} \longrightarrow \mathrm{P}=\mathrm{D}^{-1} \mathrm{~T},
$$

where $\mathbf{T}$ is the travel time per ray matrix $(1 \times n)$, $\mathbf{D}$ is the distance per ray per voxel matrix $(n \times m)$, and $\mathbf{P}$ is the slowness per grid cell matrix $(1 \times m)$.

Matrix inversion methods are effective but require considerable computational power for large datasets. Usually, the inverse problem is either underdetermined (more voxels than rays) or overdetermined (more rays than voxels). The most effective way to solve this problem is iterative process. Currently, the most referenced iterative methods are Algebraic Reconstructive Technique (ART) and Simultaneous Iterative Reconstructive Technique (SIRT) [37].

In this paper, parameters of velocity distribution and stress concentration factor were used to explore the evolution characteristics of dynamic rupture in the 1307 LCF. The time interval was from March 23 to April 14 and the size of the model is about $1000 \mathrm{~m}$ (length) $\times 800 \mathrm{~m}$ (width). After 3D location, the total mine tremors were 1519. For modeling simplification, the range of relative coordinate was $6800-8300 \mathrm{~m}$ in direction $X$ and $1400-2600 \mathrm{~m}$ in direction $Y$, respectively. Meanwhile, because the 1307 LCF elevation was approx. $750 \mathrm{~m}$, the elevation in direction $Z$ was $600-900 \mathrm{~m}$. The average velocity of $\mathrm{P}$-wave was $4.35 \mathrm{~km} / \mathrm{s}$, which was measured by laboratory tests $[26,38]$. The modeling in the tomography is depicted in Figure 8.
After modeling, the data analysis ranges in directions $X$ and $Y$ were $7000-8000 \mathrm{~m}$ and $1600-2400 \mathrm{~m}$, respectively, and the section in direction $Z$ was $750 \mathrm{~m}$. The contour map of velocity distribution is shown in Figure 9. As per the relationship [38], the contour map of stress concentration factor is displayed in Figure 10. A comparison of the two figures reveals their identicalness thus indicating that velocity could reflect stress distribution. Therefore, it is reasonable to use Figures 9 and 10 to explore the stress distribution prior to and after the dynamic rupture in the 1307 LCF.

From March 23 to March 29, high velocities in regions $A_{1}(5.8 \mathrm{~km} / \mathrm{s})$ and $A_{2}(6.0 \mathrm{~km} / \mathrm{s})$ as well as the high factors in regions $A_{1}$ (4.5) and $A_{2}$ (5.0) indicated the existence of high stress concentration in multiroadway cross area region. Similarly, high velocities in regions $B(5.8 \mathrm{~km} / \mathrm{s})$ and C $(5.5 \mathrm{~km} / \mathrm{s})$ and high factors in regions B (3.5) and C (3.0) indicated that high stress concentration was induced by mining face's frontal abutment stress. Comparatively, region $\mathrm{B}$ had a larger area and greater velocity and factor than region C, possibly induced by mined LCF (1305) coal pillar and the coal pillar (between the 1305 and 1307 LCFs) [26].

From March 30 to April 4, both area and velocities in regions $A_{1}(5.9 \mathrm{~km} / \mathrm{s})$ and $A_{2}(6.0 \mathrm{~km} / \mathrm{s})$ as well as the factors in regions $A_{1}$ (5.0) and $A_{2}$ (5.5) increased, which indicated increasing degree of high stress concentration and reduction of distance from multiroadway cross area. Simultaneously, the area and velocity in region $B(6.0 \mathrm{~km} / \mathrm{s})$ as well as the factor in region B (5.2) increased rapidly indicating that the dynamic rupture was induced by the high stress concentration (from the frontal abutment stress, mined LCF, and coal pillar). However, the overall velocity in region $\mathrm{C}$ remained unchanged thus indicating obstructive behavior towards the dynamic rupture.

From April 5 to April 9 (after the dynamic rupture occurred), the velocities and areas as well as factors in regions $A_{1}, A_{2}, B$, and $C$ all decreased (the maximum velocities were up to $5.7 \mathrm{~km} / \mathrm{s}, 5.8 \mathrm{~km} / \mathrm{s}, 5.7 \mathrm{~km} / \mathrm{s}$, and $5.4 \mathrm{~km} / \mathrm{s}$, resp.; the maximum factors were up to $5.0,4.5,3.5$, and 3 , resp.) which indicated release of high stress concentration.

From April 10 to April 14, the velocities and factors in region $A_{1}, A_{2}, B$, and $C$ all increased (the maximum velocities were up to be $6.0 \mathrm{~km} / \mathrm{s}, 6.0 \mathrm{~km} / \mathrm{s}, 5.8 \mathrm{~km} / \mathrm{s}$, and $5.5 \mathrm{~km} / \mathrm{s}$, resp.; the maximum factors were up to be 5.0, 5.0, 4.5, and 3, resp.), which indicated reoccurrence of high stress concentration because of the multiroadway cross, the frontal abutment stress, the 1305 mined LCF, and coal pillar.

From March 23 to April 14, the area of region $A_{1}$ increased and that of $\mathrm{A}_{2}$ decreased, thus indicating transfer of high stress from region $A_{2}$ to $A_{1}$ along with advancement of mining face and the reduction of coal pillar. The location of regions $\mathrm{B}$ and $\mathrm{C}$ changed/transferred with gradual advancement of the 1307 LCF. For this reason, the stress in high level could have been caused by frontal abutment pressure from the mining activity and the coal pillar belonging to static stress in high level. In region $\mathrm{D}$, the velocity (less than $4.35 \mathrm{~km} / \mathrm{s}$ ) and the factors (less than 1.0) remained lower, and the tip of the left was sensor \#5, which indicated reduced velocity following spread of seismic wave in the 1301 mined LCF [26]. 


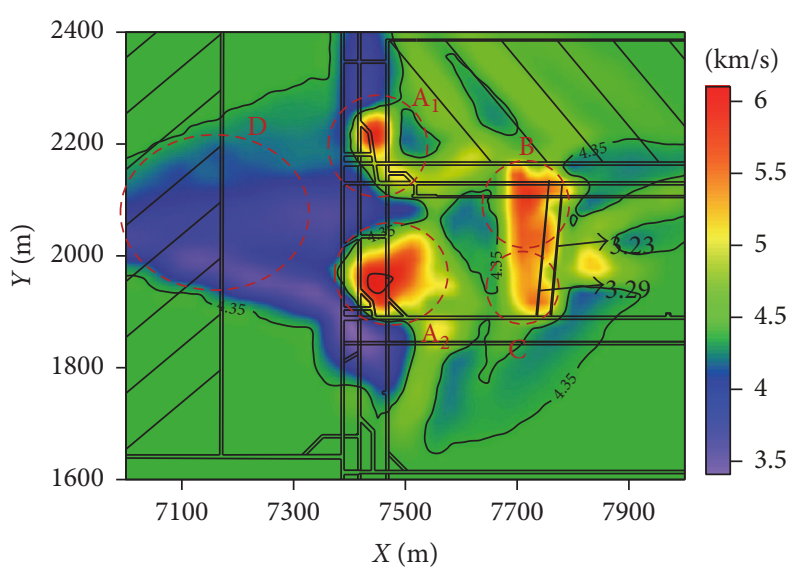

(a) March 23-March 29

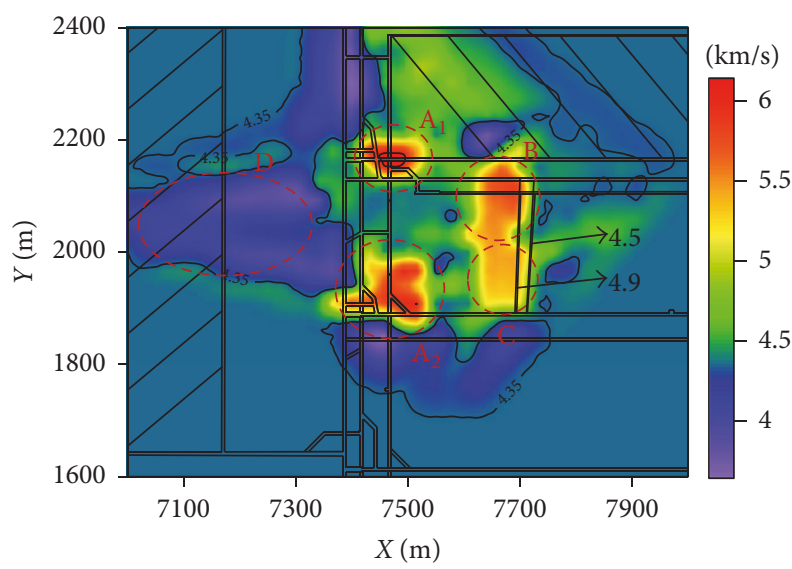

(c) April 5-April 9

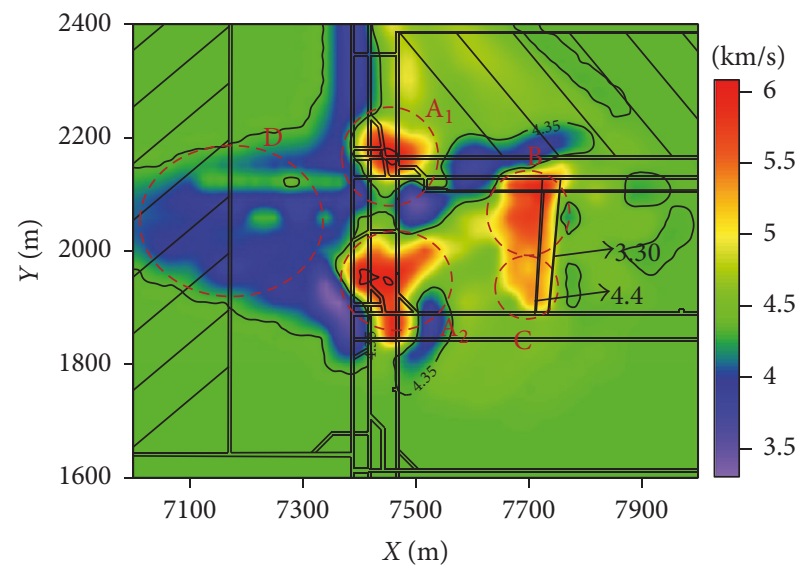

(b) March 30-April 4

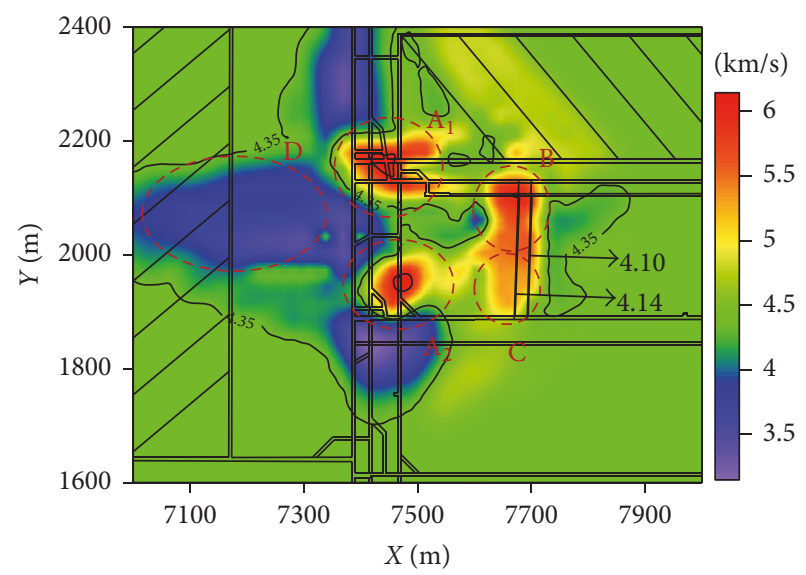

(d) April 10-April 14

FIgURE 9: The contour map of velocity distribution. The floor dynamic rupture occurred in region B.

Consequently, it was revealed that floor dynamic rupture was induced due to superposition of the high static stress concentration from the frontal and lateral abutment stresses from coal pillar and the dynamic stress from the fracture and caving of coal pillar, hard roof, and key stratum.

\section{Process Reproduction of Floor Dynamic Rupture by Numerical Simulation}

According to the geological condition of the 1307 LCF in Guojiahe Coal Mine, using numerical simulation (UDEC) a model was established to reproduce the occurrence process of floor dynamic rupture (Figure 11). The model size was $60 \times 50 \mathrm{~m}$ in length and height, and the roadway was $5 \times$ $4 \mathrm{~m}$ in length and height. The bolts were pushed into the roof and both sides of the roadway. In order to avoid errors and improve calculation efficiency, the code of Triangle was adopted in the range of $25 \times 20 \mathrm{~m}$ (around the roadway) and the code of Voronoi was used in the other range. Each block is made elastic and hence is fail safe. Failure could occur only along the contacts. The simulation parameters of block and joint were shown in Tables 2 and 3.
In the static equilibrium stage, taking into the account the simulated vertical depth $(600 \mathrm{~m})$ of the model, due to overburden $15 \mathrm{MPa}$ vertical stress was applied on the top surface of the model and along with application of $25 \mathrm{MPa}$ horizontal stress. The entire model uses fixed horizontal displacement (left and right boundaries) and vertical displacement (bottom boundary) (Figure 11). However, in dynamic analysis stage, free-field boundary conditions are applied, and the local damping is set as 0.1. In this study, after baseline correction of mine tremor before the dynamic rupture, the waveform is taken as the vibration source input wave to carry out the floor dynamic rupture numerical analysis, which is shown in Figure 11(a). After occurrence of the dynamic rupture, the cohesion and tension of the floor joints were set at zero.

The simulation results are shown in Figure 12 wherein it is evident that the whole floor dynamic rupture process, induced by shock wave disturbance, clearly recurred, with the $0.6 \mathrm{~s}$ impact time. Prior to application of dynamic loading, no obvious failure was observed in the roadway floor $(t=0 \mathrm{~s})$. Furthermore, after dynamic disturbance, it was observed that cracks initiated in the floor and converged and connected to form a weak surface with an inclined angle of $27^{\circ}(t=1.08 \mathrm{~s})$. 


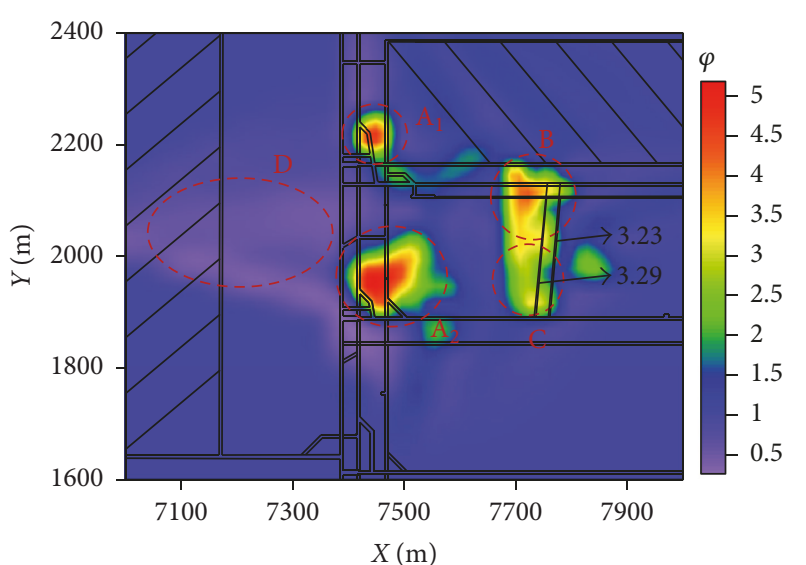

(a) March 23-March 29

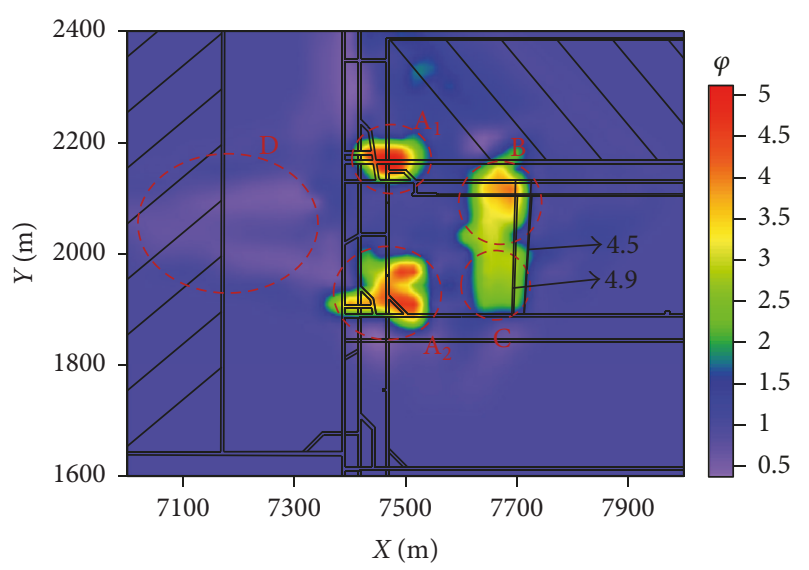

(c) April 5-April 9

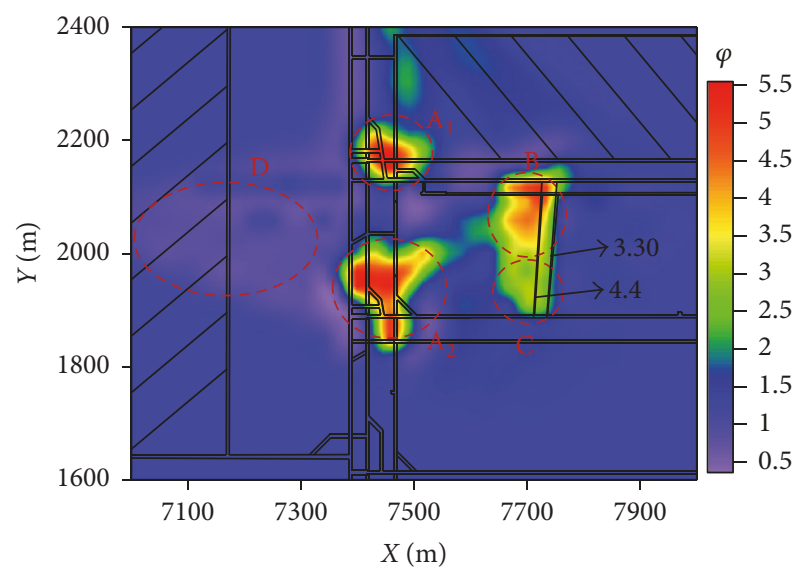

(b) March 30-April 4

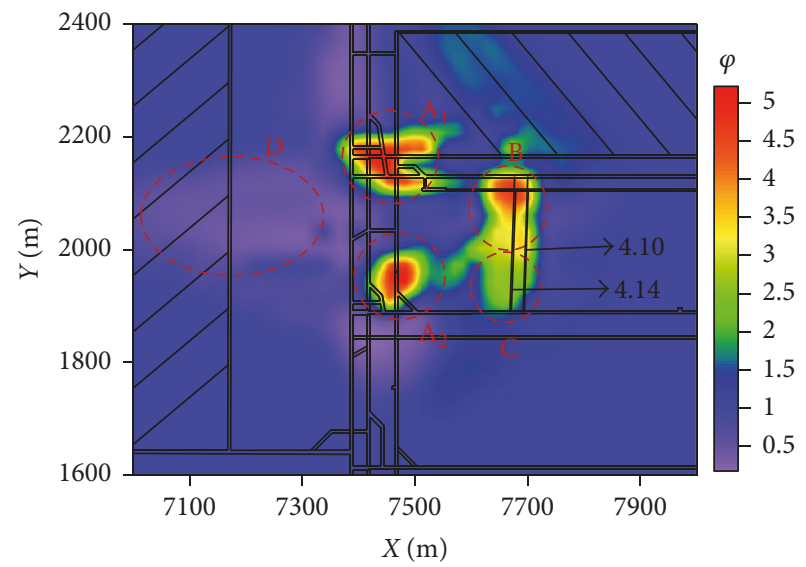

(d) April 10-April 14

FIgURE 10: The contour map of stress concentration factor. The floor dynamic rupture occurred in region B.

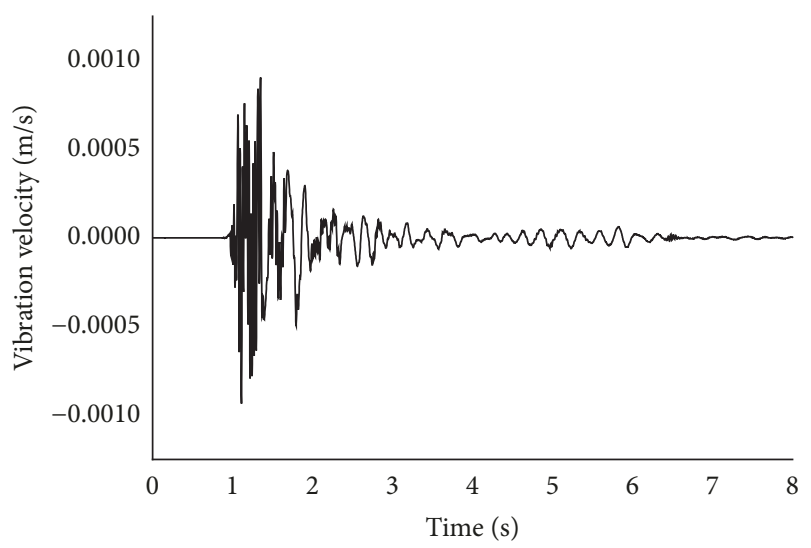

(a)

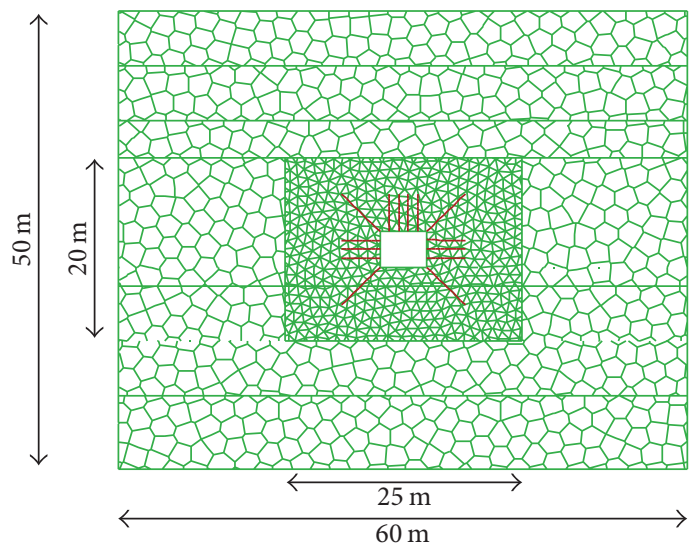

(b)

FIGURE 11: The model by UDEC. Note: (a) the source wave from a mine tremor; (b) the whole model.

With further shock wave disturbance, through shear or tension cracks begun to expand rapidly along the contacts around the weak surface ( $t=1.2 \mathrm{~s}$ ), which indicated triggering of dynamic rupture. Meanwhile, due to shock wave affect, the coal mass was ejected outward from the roadway floor $(t=1.32 \mathrm{~s})$ and was thrown into roadway at a certain velocity. After the dynamic rupture, the failure area stopped expanding $(t=1.44 \mathrm{~s})$. As the friction angle indicates, the failure in the roadway floor was not symmetrical although the symmetrical dynamic stress was generated accordingly [21]. 


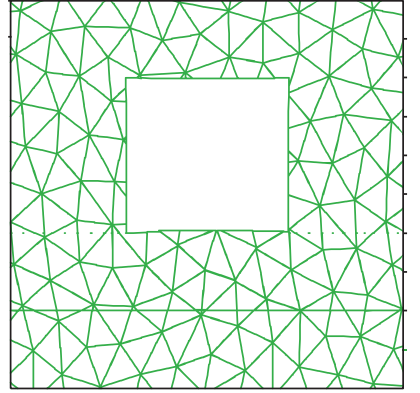

$t=0 \mathrm{~s}$

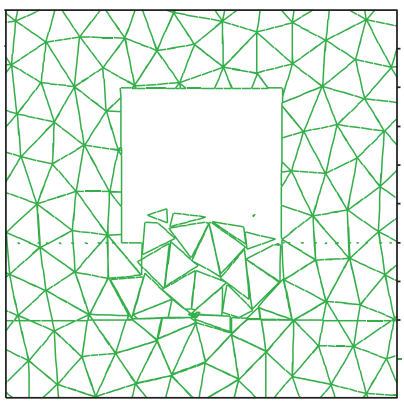

$t=1.12 \mathrm{~s}$

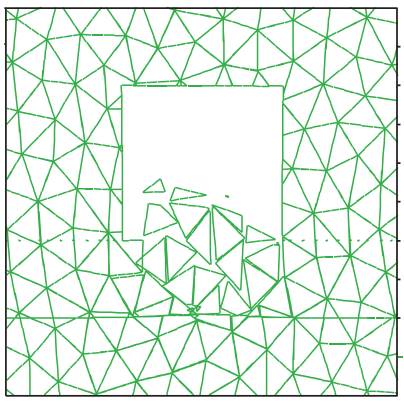

$t=1.24 \mathrm{~s}$

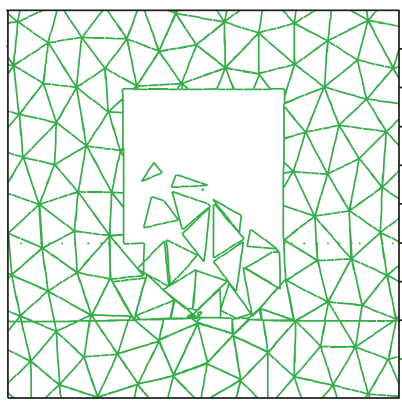

$t=1.36 \mathrm{~s}$

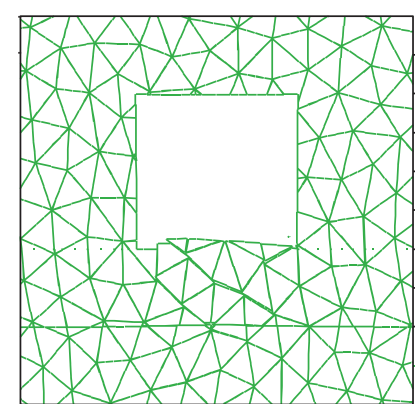

$t=1.04 \mathrm{~s}$

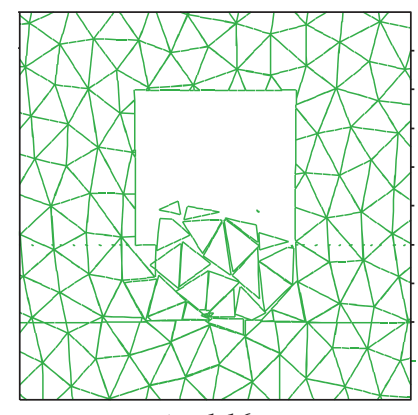

$t=1.16 \mathrm{~s}$

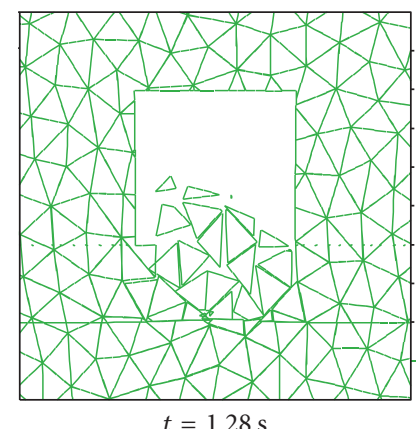

$t=1.28 \mathrm{~s}$

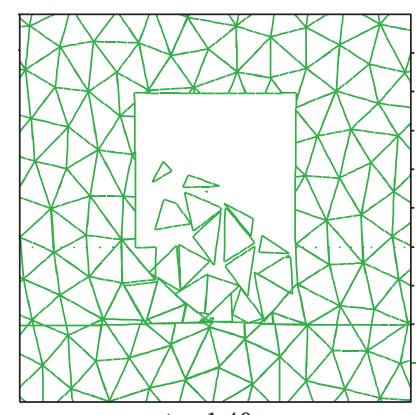

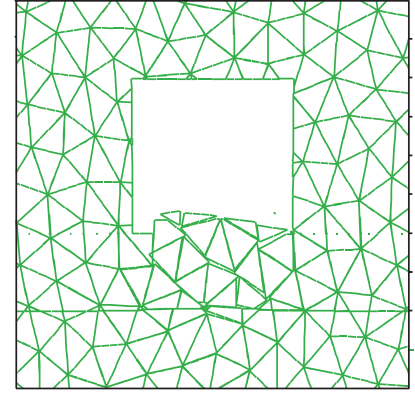

$t=1.08 \mathrm{~s}$

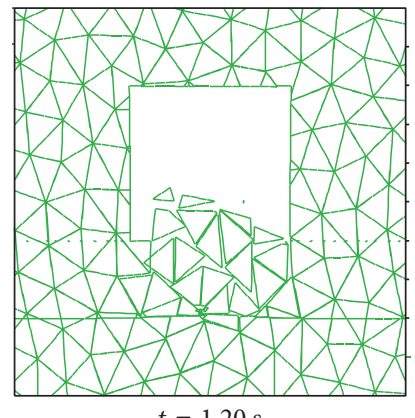

$t=1.20 \mathrm{~s}$

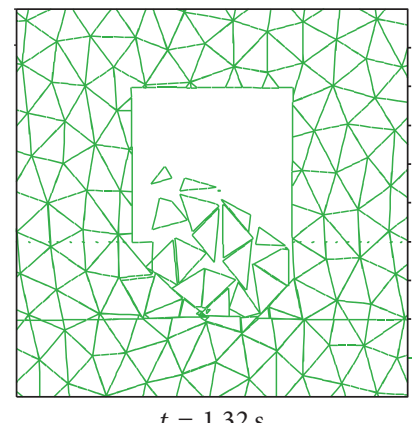

$t=1.32 \mathrm{~s}$

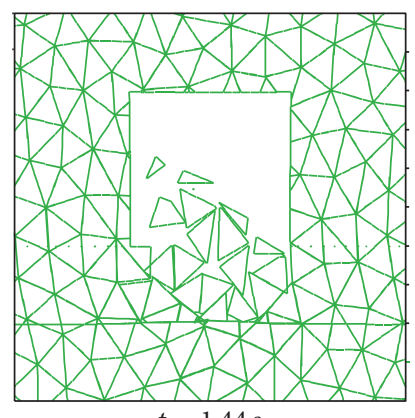

$t=1.44 \mathrm{~s}$

Figure 12: Process simulation of floor dynamic rupture. Note: before $t=1.0 \mathrm{~s}$, it is static stage; after $t=1.0 \mathrm{~s}$, it is dynamic stage.

According to the above analysis, assuming that the released energy was converted into the kinetic energy of rock blocks wholly, we put forward a method to calculate the kinetic energy as follows:

$$
E_{k}=\frac{1}{2} \sum_{i=1}^{n} \rho s_{i} v_{i}^{2}
$$

where $E_{k}$ is the kinetic energy of rock blocks in floor; $\rho$ is the density; $s_{i}$ is the area in $x-y$ plane; $v_{i}$ is the maximum velocity in $y$-direction. A fish function is used to obtain $s_{i}$ and $v_{i}$.
In (8), the factor of horizontal stress has an effect on floor failure. Therefore, its effect on the kinetic energy was carried out, as shown in Figure 13. From Figure 13, the kinetic energy increases almost exponentially with the horizontal stress increasing, which indicates the horizontal stress is the key factor to floor dynamic rupture.

Figure 14 is the evolution characteristic of horizontal stress in floor rupture process. Figures (a), (b), and (c) are in static stage; Figures (d) and (e) are in dynamic stage. In static stage, the horizontal stress in the floor reduces gradually as 
TABLE 2: The parameters of blocks.

\begin{tabular}{lccc}
\hline Lithology & Density $/\left(\mathrm{Kg} / \mathrm{m}^{3}\right)$ & Bulk modulus/GPa & Shear modulus/GPa \\
\hline Fine sandstone & 2550 & 18.4 & 9.6 \\
Siltstone & 2510 & 12.2 & 6.6 \\
Mudstone & 2500 & 8.1 & 3.1 \\
$3^{\#}$ coal & 1400 & 3.05 & 2.1 \\
Mudstone & 2500 & 8.1 & 3.1 \\
Siltstone & 2510 & 12.2 & 6.6 \\
Fine sandstone & 2550 & 18.4 & 9.6 \\
\hline
\end{tabular}

TABLE 3: The parameters of joints.

\begin{tabular}{|c|c|c|c|c|c|}
\hline Lithology & Normal stiffness/GPa & Shear stiffness/GPa & Friction angle $/^{\circ}$ & Cohesion/MPa & Tension/MPa \\
\hline Fine sandstone & 7500 & 3100 & 26 & 15.8 & 6.4 \\
\hline Siltstone & 5200 & 2100 & 25 & 10.3 & 5.6 \\
\hline Mudstone & 3300 & 1400 & 20 & 8.2 & 3.2 \\
\hline $3^{\#}$ coal & 2000 & 800 & 18 & 3.0 & 1.1 \\
\hline Mudstone & 3300 & 1400 & 20 & 8.2 & 3.2 \\
\hline Siltstone & 5200 & 2100 & 25 & 10.3 & 5.6 \\
\hline Fine sandstone & 7500 & 3100 & 26 & 15.8 & 6.4 \\
\hline
\end{tabular}

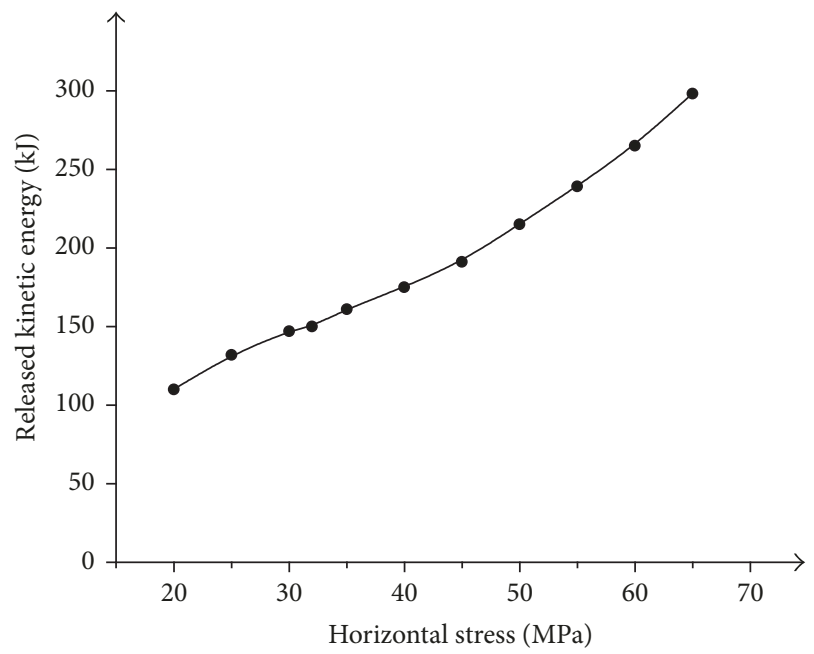

FIGURE 13: The effect of horizontal stress on the released kinetic energy.

well as the horizontal stress in both sides. In dynamic stage, the horizontal stress in the floor reduces rapidly and even becomes tensile stress.

\section{Conclusions}

The floor heave activity within a given time frame corresponds to the dynamic rupture, which earlier had caused severe threats to mine workers and affected continuous production in coal mines. In order to explore the mechanism of floor dynamic rupture, this paper adopts a thin plate model to investigate the floor failure condition. The floor dynamic rupture risk was positively related to roadway width and horizontal stress but negatively related to the thickness. Subsequently, the high stress concentration caused the floor to buckle, and the dynamic disturbance led to the rapid release of large elastic energy, which could induce dynamic rupture. Using the parameters of P-velocity distribution and stress concentration factor, the evolution characteristics of dynamic rupture were explored in the 1307 LCF, and the regions of tailentry and local 1307 LCF experienced higher wave velocity prior to the dynamic rupture and lower wave velocity after the dynamic rupture. Meanwhile, the evolution of mine tremors revealed the accumulation and subsequent release of energy in the dynamic rupture process and the presence of mine tremors with large energy. It was found that superposition of the high static stress concentration from the frontal and lateral abutment stress from the coal pillar and the dynamic stress from the fracturing and caving of coal pillar, hard roof, and key stratum induced the floor dynamic rupture. Finally, the occurrence process of floor dynamic rupture was reproduced by numerical simulation within $0.6 \mathrm{~s}$ time frame setting. The findings mentioned above could be used to propose a certain reference for earlier warning and prevention of the floor dynamic rupture using seismic computed tomography and location of mine tremors.

\section{Conflicts of Interest}

The authors declare that they have no conflicts of interest.

\section{Acknowledgments}

The authors gratefully acknowledge financial support for this work provided by the Fundamental Research Funds for the Central Universities (2018ZDPY02), State Key Laboratory of Coal Resources and Safe Mining, CUMT (SKLCRSM16X02), 


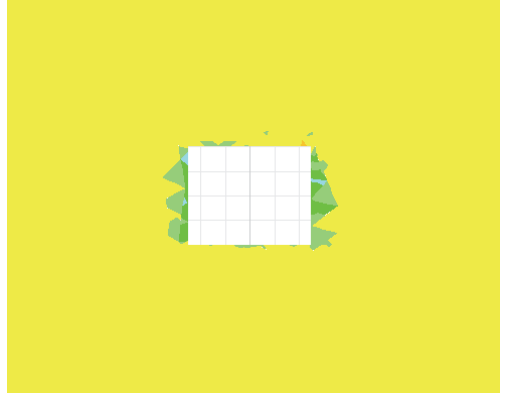

(a) $t=0.001 \mathrm{~s}$

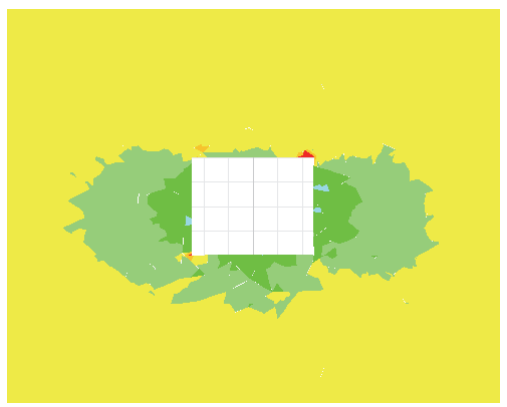

(c) $t=0.008 \mathrm{~s}$
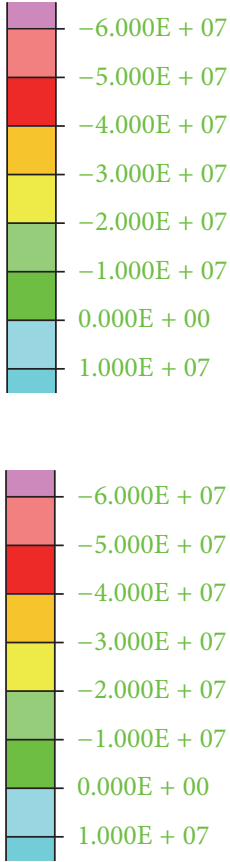

$+07$
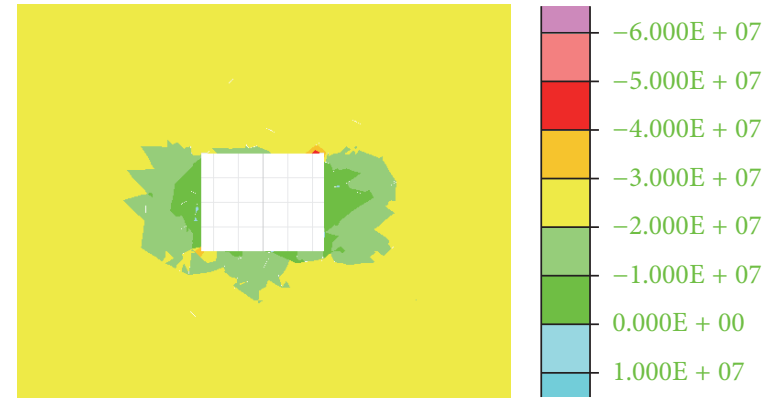

(b) $t=0.004 \mathrm{~s}$
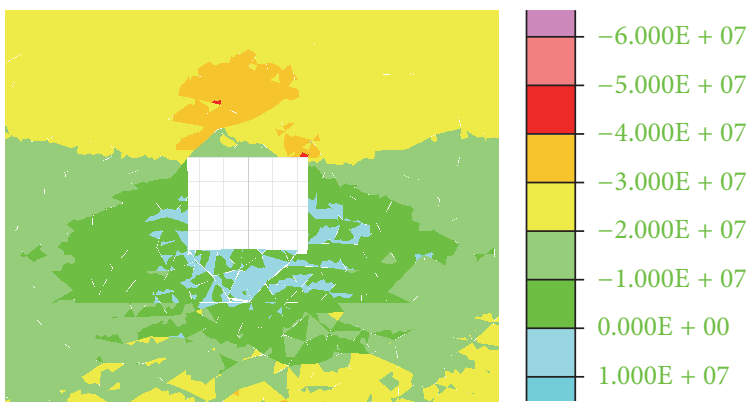

(d) $t=0.02 \mathrm{~s}$
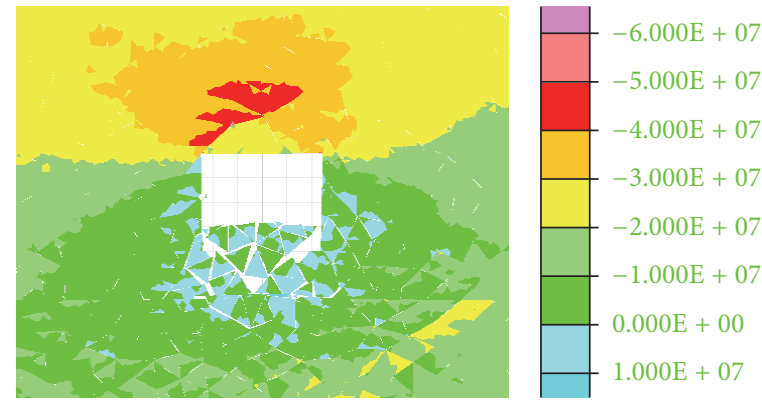

(e) $t=0.10 \mathrm{~s}$

Figure 14: The evolution characteristic of horizontal stress. Note: Figures (a), (b), and (c) are in static stage; Figures (d) and (e) are in dynamic stage.

and the Priority Academic Program Development of Jiangsu Higher Education Institutions (PAPD).

\section{References}

[1] L. M. Dou and X. Q. He, Theory and Technique on Rockburst Prevention, China University of Mining and Technology Press, 2001.

[2] Q. Chang, H. Zhou, Z. Xie, and S. Shen, "Anchoring mechanism and application of hydraulic expansion bolts used in soft rock roadway floor heave control," International Journal of Mining Science and Technology, vol. 23, no. 3, pp. 323-328, 2013.

[3] Y. D. Jiang, Y. X. Zhao, and W. G. Liu, "Research on floor heave of roadway in deep mining," Journal of Rock Mechanics and Engineering, vol. 23, no. 14, pp. 2396-2401, 2004 (Chinese).

[4] J. Sun and L. Wang, "Numerical simulation of grooving method for floor heave control in soft rock roadway," Mining Science and Technology, vol. 21, no. 1, pp. 49-56, 2011.
[5] L. C. Li and H. H. Liu, "A numerical study of the mechanical response to excavation and ventilation around tunnels in clay rocks," International Journal of Rock Mechanics and Mining Sciences, vol. 59, pp. 22-32, 2013.

[6] P. Lin, Y. Zhou, H. Liu, and C. Wang, "Reinforcement design and stability analysis for large-span tailrace bifurcated tunnels with irregular geometry," Tunnelling and Underground Space Technology, vol. 38, pp. 189-204, 2013.

[7] Y. Zhao, N. Liu, X. Zheng, and N. Zhang, "Mechanical model for controlling floor heave in deep roadways with U-shaped steel closed support," International Journal of Mining Science and Technology, vol. 25, no. 5, pp. 713-720, 2015.

[8] Y. Xu, J. Chen, and J. Bai, "Control of floor heaves with steel pile in gob-side entry retaining," International Journal of Mining Science and Technology, vol. 26, no. 3, pp. 527-534, 2016.

[9] S. Jeon, J. Kim, Y. Seo, and C. Hong, "Effect of a fault and weak plane on the stability of a tunnel in rock-a scaled model test and numerical analysis," International Journal of Rock 
Mechanics and Mining Sciences, vol. 41, supplement 1, pp. 658663, 2004.

[10] Y.-Z. Lee and W. Schubert, "Determination of the round length for tunnel excavation in weak rock," Tunnelling and Underground Space Technology, vol. 23, no. 3, pp. 221-231, 2008.

[11] S. B. Tang and C. A. Tang, "Numerical studies on tunnel floor heave in swelling ground under humid conditions," International Journal of Rock Mechanics and Mining Sciences, vol. 55, pp. 139-150, 2012.

[12] Z. Zhong, Y. Tu, and X. Liu, "Occurrence mechanism and control technology of the floor heave disaster for soft-rock tunnel," Disaster Advances, vol. 5, no. 4, pp. 987-992, 2012.

[13] Z. Li, L. Dou, W. Cai et al., "Investigation and analysis of the rock burst mechanism induced within fault-pillars," International Journal of Rock Mechanics and Mining Sciences, vol. 70, pp. 192200, 2014.

[14] J. He, L.-M. Dou, Z.-L. Mu, A.-Y. Cao, and S.-Y. Gong, "Numerical simulation study on hard-thick roof inducing rock burst in coal mine," Journal of Central South University, vol. 23, no. 9, pp. 2314-2320, 2016.

[15] A.-Y. Cao, L.-M. Dou, C.-B. Wang, X.-X. Yao, J.-Y. Dong, and Y. Gu, "Microseismic precursory characteristics of rock burst hazard in mining areas near a large residual coal pillar: a case study from xuzhuang coal mine, xuzhou, China," Rock Mechanics and Rock Engineering, vol. 49, no. 11, pp. 1-16, 2016.

[16] A. Fakhimi, O. Hosseini, and R. Theodore, "Physical and numerical study of strain burst of mine pillars," Computers and Geosciences, vol. 74, pp. 36-44, 2016.

[17] Z.-L. Li, L.-M. Dou, W. Cai, G.-F. Wang, Y.-L. Ding, and Y. Kong, "Mechanical analysis of static stress within fault-pillars based on a voussoir beam structure," Rock Mechanics and Rock Engineering, vol. 49, no. 3, pp. 1097-1105, 2016.

[18] G. Zhu, L. Dou, Y. Liu et al., "Dynamic behavior of fault slip induced by stress waves," Shock and Vibration, vol. 2016, Article ID 4386836, 13 pages, 2016.

[19] G.-X. Chen, L.-M. Dou, and Z.-R. Wang, "The study on prevention of rockburst when mining in folding structure areas," in Proceedings of the 2011 Asia-Pacific Power and Energy Engineering Conference, APPEEC 2011, China, March 2011.

[20] A. N. Shabarov, "On formation of geodynamic zones prone to rock bursts and tectonic shocks," Journal of Mining Science, vol. 37, no. 2, pp. 129-139, 2001.

[21] C.-P. Lu, G.-J. Liu, H.-Y. Wang, and J.-H. Xue, "Numerical investigation of rockburst effect of shock wave on underground roadway," Shock and Vibration, vol. 2015, Article ID 867582, 10 pages, 2015.

[22] L. Sun, H. Ji, B. Yang, and L. Zhang, "Simulation analysis of influence of floor weak interlayer on floor heave in deep mining roadway," Journal of Mining Engineering and Safety, vol. 31, no. 5, pp. 695-701, 2014 (Chinese).

[23] Q. Z. Qu, Q. Zhang, Q. Z. Ji, and X. F. Liang, Theory of Elastic Plate, China Communications Press, 2000.

[24] L. Y. Wu, Theory of Plates and Shells, Shanghai Jiaotong University Press, 1989.

[25] T. Parsons, "Persistent earthquake clusters and gaps from slip on irregular faults," Nature Geoscience, vol. 1, no. 1, pp. 59-63, 2008.

[26] C.-P. Lu, G.-J. Liu, N. Zhang, T.-B. Zhao, and Y. Liu, "Inversion of stress field evolution consisting of static and dynamic stresses by microseismic velocity tomography," International Journal of Rock Mechanics and Mining Sciences, vol. 87, pp. 8-22, 2016.
[27] L. Dong, D. Sun, X. Li, and K. Du, “Theoretical and experimental studies of localization methodology for $\mathrm{AE}$ and microseismic sources without pre-measured wave velocity in mines," IEEE Access, vol. 5, pp. 16818-16828, 2017.

[28] L. Dong, W. Zou, X. Li, W. Shu, and Z. Wang, "Collaborative localization method using analytical and iterative solutions for microseismic/acoustic emission sources in the rockmass structure for underground mining," Engineering Fracture Mechanics, pp. 1-18, 2018.

[29] L. Dong, J. Wesseloo, Y. Potvin, and X. Li, "Discrimination of mine seismic events and blasts using the fisher classifier, naive bayesian classifier and logistic regression," Rock Mechanics and Rock Engineering, vol. 86, no. 1, pp. 282-291, 2016.

[30] G. Liu, Z. Mu, and M. Karakus, "Coal burst induced by rock wedge parting slip: a case study in Zhaolou coal mine," International Journal of Mining, Reclamation and Environment, pp. $1-15,2017$.

[31] L. Dong, J. Wesseloo, Y. Potvin, and X. Li, "Discrimination of mine seismic events and blasts using the fisher classifier, naive bayesian classifier and logistic regression," Rock Mechanics and Rock Engineering, vol. 49, no. 1, pp. 183-211, 2016.

[32] L. Dong, W. Shu, X. Li, G. Han, and W. Zou, “Three dimensional comprehensive analytical solutions for locating sources of sensor networks in unknown velocity mining system," IEEE Access, vol. 5, pp. 11337-11351, 2017.

[33] M. Ge, H. Wang, H. R. Hardy Jr., and R. Ramani, "Void detection at an anthracite mine using an in-seam seismic method," International Journal of Coal Geology, vol. 73, no. 3-4, pp. 201212, 2008.

[34] L. Dou, T. Chen, S. Gong, H. He, and S. Zhang, "Rockburst hazard determination by using computed tomography technology in deep workface," Safety Science, vol. 50, no. 4, pp. 736-740, 2012.

[35] W. Cai, L. Dou, A. Cao, S. Gong, and Z. Li, "Application of seismic velocity tomography in underground coal mines: a case study of Yima mining area, Henan, China," Journal of Applied Geophysics, vol. 109, pp. 140-149, 2014.

[36] W. Cai, L. Dou, S. Gong, Z. Li, and S. Yuan, "Quantitative analysis of seismic velocity tomography in rock burst hazard assessment," Natural Hazards, vol. 75, no. 3, pp. 2453-2465, 2014.

[37] K. Luxbacher, E. Westman, P. Swanson, and M. Karfakis, "Three-dimensional time-lapse velocity tomography of an underground longwall panel," International Journal of Rock Mechanics and Mining Sciences, vol. 45, no. 4, pp. 478-485, 2008.

[38] S.-Y. Gong, L.-M. Dou, J. He, H. He, C.-P. Lu, and Z.-L. Mu, "Study of correlation between stress and longitudinal wave velocity for deep burst tendency coal and rock samples in uniaxial cyclic loading and unloading experiment," Rock and Soil Mechanics, vol. 33, no. 1, pp. 41-47, 2012 (Chinese). 


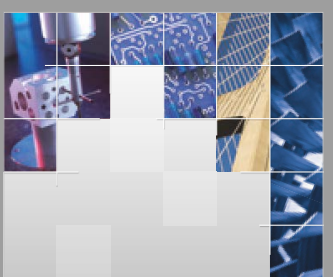

\section{Enfincering}
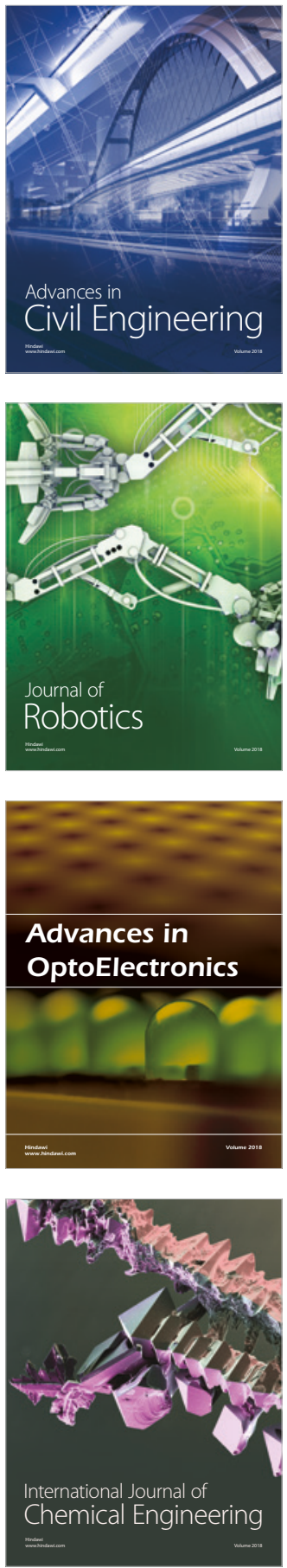

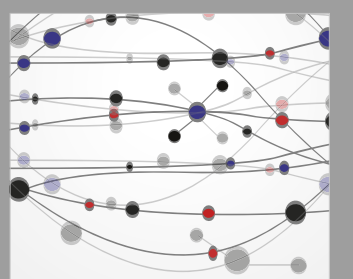

\section{Rotating \\ Machinery}

The Scientific World Journal

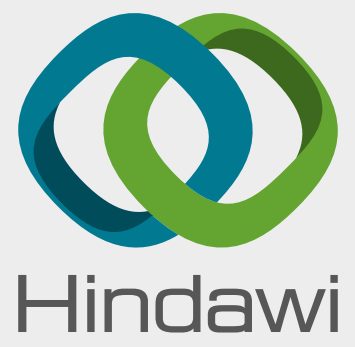

Submit your manuscripts at

www.hindawi.com
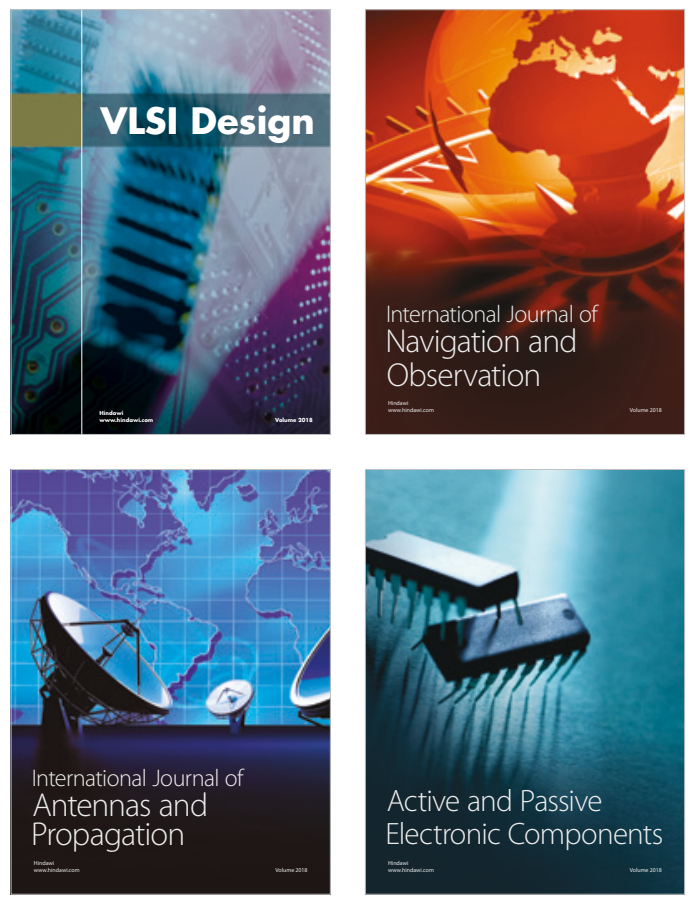
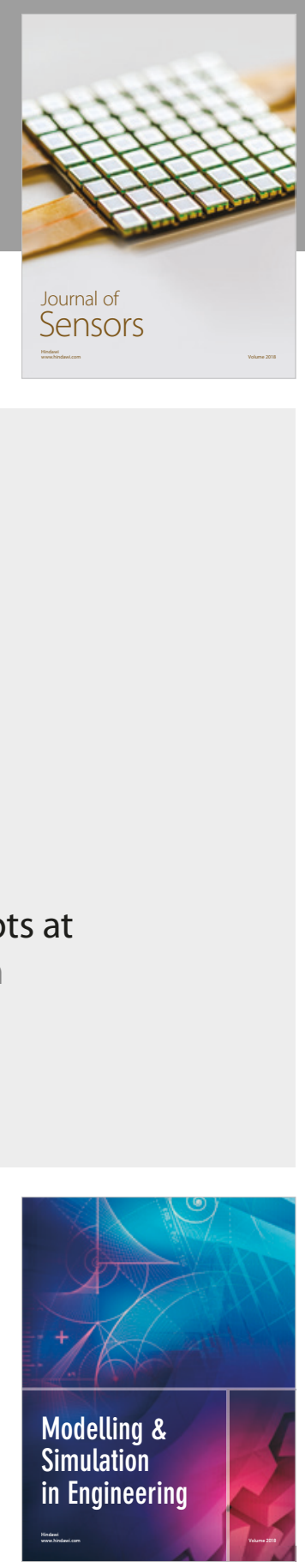

\section{Advances \\ Multimedia}
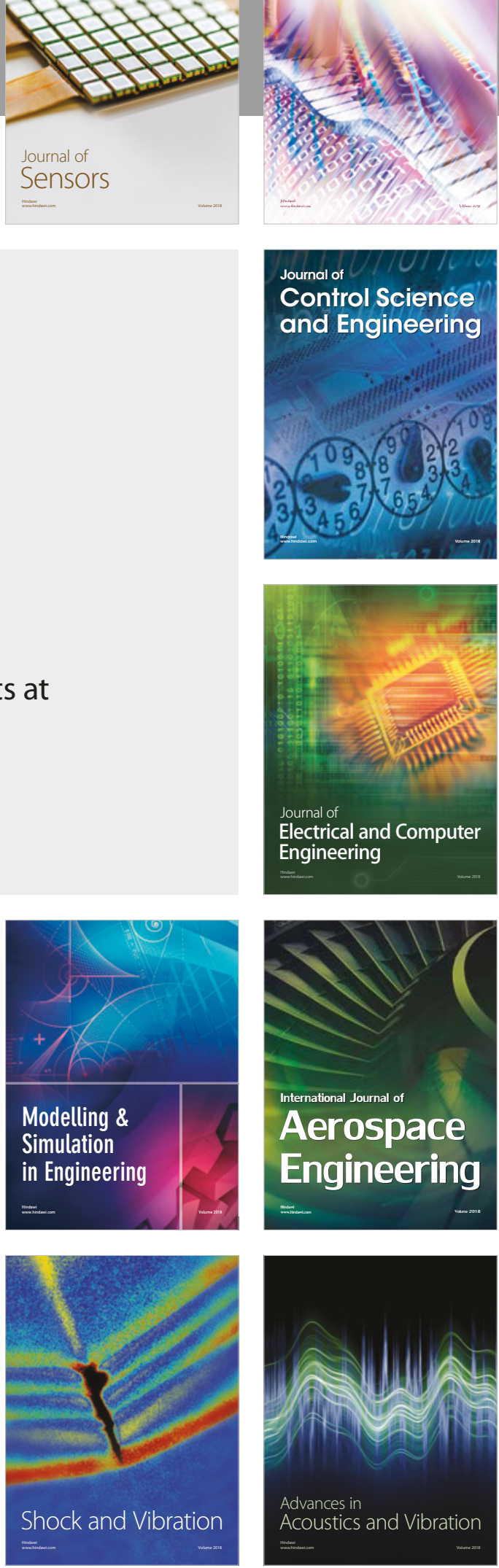